맥락막혈과녕응에 대한 광역학 치료 후 발생한 광범위 장액망막박리

\title{
Extensive Serous Retinal Detachment after Photodynamic Therapy for Polypoidal Choroidal Vasculopathy
}

\author{
이택훈 ${ }^{1}$, 이상준 ${ }^{2}$, 남기엽 ${ }^{2}$ \\ Taek Hoon Lee', Sang Joon Lee ${ }^{2}$, Ki Yup Nam² \\ ${ }^{1}$ 대전 이안과병원, ${ }^{2}$ 고신대학교 의과대학 안과학교실 \\ ${ }^{1}$ Rhee's Eye Hospital, Daejeon, Korea \\ ${ }^{2}$ Department of Ophthalmology, Kosin University College of Medicine, Busan, Korea
}

Purpose: To report a case with extensive serous retinal detachment (SRD) after photodynamic therapy (PDT) for polypoidal choroidal vasculopathy (PCV)

Case summary: A 72 year old man visited our clinic complaining of visual disturbance in the left eye for 1 week. Visual acuity (VA) was finger counting at $30 \mathrm{~cm}$ in the left eye. The fundus was invisible due to vitreous hemorrhage, and so vitrectomy was performed; atrophic scar on the posterior pole and extensive subretinal hemorrhage over the inferior retina were seen during surgery. One week after surgery, best corrected visual acuity was 0.075 . Three weeks after vitrectomy, large pigment epithelial detachment superior to the fovea and cystic lesions in the retina were seen on optical coherence tomography, and a branching vascular network and polyps were found on indocyanine green angiography. Thus, PDT was performed for PCV treatment. Two weeks after PDT, the patient complained of decreased vision and superior visual field defect. On fundus examination, extensive retinal detachment (RD) reaching below the fovea was found, but no retinal break or hole was found. Thus, intravitreal anti-vascular endothelial growth factor injection had been performed at 5 months. However, RD gradually progressed to fovea and subretinal fibrosis was developed. Surgical treatment with retinotomy, subretinal fluid drainage and fluid-gas exchange was performed. The retina was flattened after surgery and VA recovered to 0.1.

Conclusions: Transient SRD is often seen after PDT for age related macular degeneration or PCV, but extensive SRD is very rare. Surgical treatment may be another treatment option in such cases.

Keywords: Polypoidal choroidal vasculopathy; Photodynamic therapy; Serous retinal detachment

Address reprint requests to Ki Yup Nam, MD

Department of Ophthalmology, Kosin University Gospel Hospital, \#262 Gamcheon-ro, Seo-gu, Busan 49267, Korea Tel: 82-51-990-6471, Fax: 82-51-990-3026

E-mail:oksnam1231@daum.net
Received: 2016. 4. 22

Revised: 2016.4.30

Accepted: 2016. 5. 2 


\section{서론}

연령관련 황반변성(age related macular degeneration, AMD) 에 대한 광역학 치료(photodynamic therapy, PDT)의 효과는 Verteporfin in Photodynmic Therapy Study (VIP), Treatment of Age Related Macular Degeneration with Photodynamic Therapy (TAP) 연구 등을 통해 이미 널리 알려져 왔다[1-3]. 또한 결절맥락막혈관병증에 대해서는 Ranibizumab과의 비교 연구 인 efficacy and safety of verteporfin photodynamic therapy in combination with ranibizumab or alone versus ranibizumab monotherapy in patients with symptomatic macular polypoidal choroidal vasculopathy (EVEREST) 연구에서 PDT가 결절을 소 실시키는 데 더 효과가 있음이 밝혀졌다[4].

PDT는 광과민성을 띠는 verteporfin을 이용하는데, 정맥주 사를 통해 신생혈관에 도달하면 내피세포의 low density lipid (LDL) 단백 수용체와 결합하게 된다. 이 부위에 $689 \mathrm{~nm}$ 의 다 이오드 레이저를 조사하면 verteporfin이 활성화되는데 이로 인 해 활성산소와 자유 유리기가 발생하고 내피세포 손상이 일어 나며 혈관기저막 노출 및 혈소판 응집이 뒤따라 일어나 혈관을 폐쇄시킨다[5].

연령관련 황반변성에 대한 PDT의 합병증은 드문 것으로 알려 져 있다. VIP와 TAP 연구 환자들을 대상으로 PDT의 안전성에
대해서 메타 분석한 연구에서는 위약군과 비교했을 때 전신적 혹은 안과적 합병증의 차이는 없었다[6]. 안과적으로 가장 흔한 합병증은 시력 장애였는데 대부분 일시적이고 경하였으며 급성 의 심한 시력 저하는 0.7-4.9\%에서 나타났다. 심한 시력 저하의 원인으로는 망막하액의 증가, 망막하출혈, 녹색의 황반하병변 등이 확인되었는데 망막하액 증가의 경우 3 개월 내에 모든 증 례에서 흡수되었다[7].

한편, Mennel et al. [8]은 연령관련 황반변성에 대한 PDT 후 초기에 일시적인 장액망막박리가 나타나며 이는 PDT 후 신생 혈관 누출 증가 및 외측 혈액망막장벽의 파괴와 관련이 있다고 하였다. 하지만 지금까지 연령관련 황반변성에 대한 PDT 후 지 속적인 장액망막박리에 대한 보고는 찾아보기 어렵다. 저자들 은 결절맥락막병증에 대한 PDT 후 초기에 광범위한 장액망막 박리가 발생하고 지속적으로 유지되어 수술적 치료로 망막을 재유착시킨 증례를 경험하여 이를 보고하고자 한다.

\section{증례보고}

72세 남자 환자가 좌안의 시력저하를 주소로 내원하였다. 내원 당시 시력은 양안 모두 안전수지 $30 \mathrm{~cm}$ 로 측정되었으며 교정되 지 않았다. 과거력상 약 5년 전 양안의 연령관련황반변성 및 개

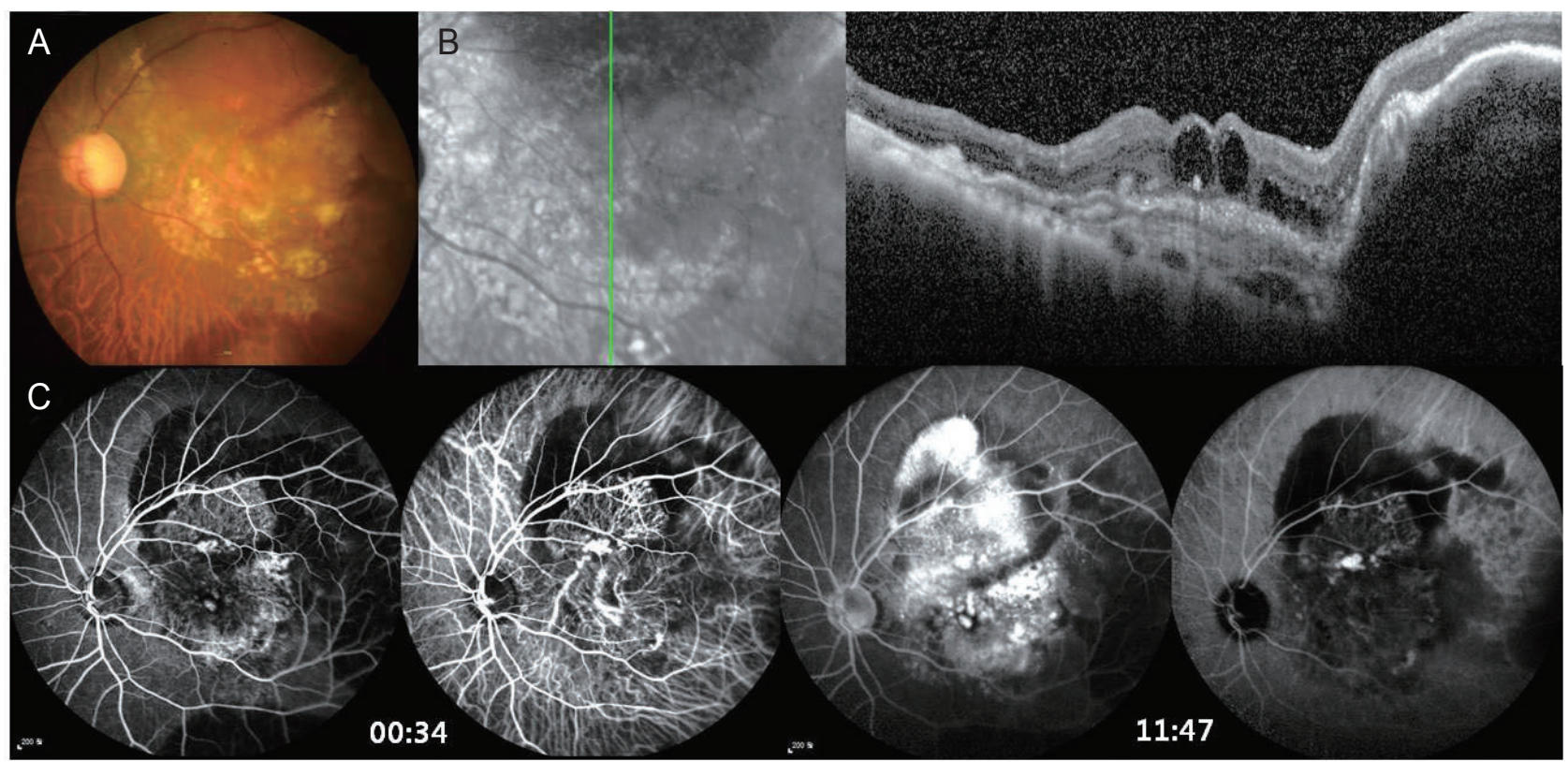

Figure 1. Examinations 3 weeks after initial vitrectomy for breakthrough vitreous hemorrhage. (A) Atrophic lesions are over the posterior pole area and large retinal pigment epithelium detachment (PED) superior to fovea is also found on fundus examination. (B) Optical coherence tomography shows intraretinal cysts and large PED. (C) Indocyanine green angiography shows branching retinal vascular network and polyps. 


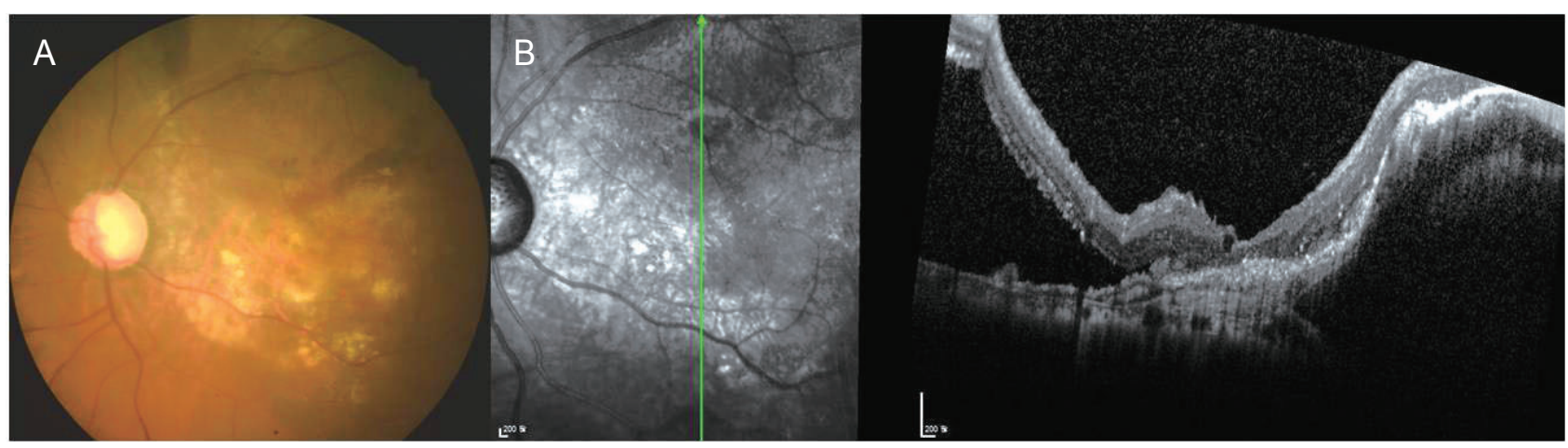

Figure 2. Fundus examination and optical coherence tomography (OCT) 2 weeks after photodynamic therapy. (A) On fundus examination, retina below the fovea seems to be slightly opaque and choroidal vessels are invisible. (B) OCT also shows inferior retinal detachment reaching the fovea.

방각녹내장으로 본원에서 진료 받았으며 당시 최대교정시력은 우안 안저수지 $30 \mathrm{~cm}$, 좌안 0.25 였다. 당시 우안 안저검사 및 빛 간섭단층촬영(optical coherence tomography, OCT)에서는 위축 성 반흔 및 큰 망막 내 낭포로 인한 망막비후를 보였으며 좌안 에서는 후극부의 광범위한 망막색소상피박리(pigment epitheli소 al detachment, $\mathrm{PED}$ )가 관찰되었다. 인도시아닌그린혈관조영술 (indocyanine green angiography, ICGA)에서 선형혈관 및 결절 이 관찰되어 결절맥락막혈관병증(polypoidal choroidal vasculopahty, PCV)으로 판단되어 좌안에 anti-vascular endothelial growth factor (VEGF) 주입술을 시행하며 정기적인 진료를 시 행하던 중 환자 사정으로 2년간 내원하지 않았다. 당뇨병 및 고 혈압 과거력은 없었으며 특별한 외상력도 없었다.

전안부 검사에서 중등도의 핵백내장 이외에 특이 소견은 보 이지 않았고 안저검사에서는 우안은 초진 시와 큰 차이를 보이 지 않았으나 좌안에는 유리체출혈이 관찰되고 이로 인해 안저 를 확인할 수 없었다. 이에 결절맥락막혈관병증과 연관된 유리 체출혈(breakthrough vitreous hemorrhage)이라고 판단한 후 유 리체절제술, 수정체초음파유화술, 인공수정체삽입술, 유리체강 내 bevacizumab 주입술을 시행하였다. 수술 중 후극부의 위축 성 병변 및 하부의 광범위한 망막하 출혈을 관찰할 수 있었으며 특별한 문제는 발생하지 않았다.

수술 2 주 후 좌안의 최대 교정 시력은 0.075 였으며 환자는 유 리체출혈 발생 전의 시력과 비슷하다고 하였다. 수술 4주 후 시행한 플루레신 형광안저혈관조영술(fluorescein angiography, $\mathrm{FA}$ ) 및 ICGA에서 방사상으로 가지를 치는 선형 혈관 및 결절, 이상혈관으로부터의 누출이 관찰되고 OCT에서 황반부 위쪽에 큰 망막색소상피박리 및 황반부의 망막 내 낭성 병변이 관찰되 었다(Fig. 1). 이에 결절맥락막혈관병증에 대한 치료로서 PDT 를 시행하였다. 체표면적 $\left(\mathrm{m}^{2}\right)$ 당 $6 \mathrm{mg}$ 의 verteporfin (Visudyne,
Novartis AG, Basel, Switzerland)을 10분간에 걸쳐 정맥 주사하 였고, 5 분 후에 다이오드 레이저를 조사하였다. 결절과 선형혈 관을 포함하여 지름 $4,500 \mu \mathrm{m}$ 의 원 영역에 시행하였으며 표준 치료 세기인 $50 \mathrm{~J}, 600 \mathrm{mw}$ 의 세기로 83초간 조사하였다.

$\mathrm{PDT} 1$ 주 후 환자가 좌안의 시력이 저하된 것 같다고 호소하 였다. 교정시력은 0.05 였으며 전안부에는 특별한 소견은 보이지 않았다. 안저검사에서 큰 변화는 확인할 수 없었고 OCT에서는 황반부 위쪽 PED 근처로 망막하액이 고여있는 것을 확인할 수 있었다. PDT 후 일시적인 장액성 망막하액은 드물지 않은 소견 이므로 1 개월 후 다시 경과 관찰하기로 하였으나 시술 2주째 환 자가 좌안 상측 시야가 점점 좁아진다고 하여 다시 내원하였다. 안저검사에서 하부의 망막박리가 황반부 바로 아래까지 침범하 여 있는 것이 확인되었고 이는 황반부 상측의 PED로부터 황반 부 이측의 망막하 경로를 통해 연결되어 있었다(Fig. 2). 망막 주 변부에는 열공은 관찰되지 않았다. 안저검사를 누운 자세와 앉 은 자세에서 시행한 결과 망막하액의 이동을 확인할 수 있었다.

이에 장액망막박리로 추정하고 항혈관내피성장인자를 유리체 강내로 주사하고 경과 관찰하였다. 1 개월 간격으로 bevacizumab 2회, aflibercept 2회 주사 후에도 망막박리는 호전되지 않았다. 비록 망막박리가 황반부를 침범하지는 않았고 시력은 0.1 로 유 지되었으나 망막박리가 점차 황반부로 진행하는 소견을 보이고 망막주름 및 망막하 섬유성 띠가 발생하여 PDT 후 5 개월째 결 국 수술을 결정하였다. 시신경 비측에 망막절개를 하고 망막하 액을 배액한 후 C3F8 (18\%)을 충전하였다. 수술 중에도 주변부 망막의 열공은 발견하지 못했다. 수술 후 3 개월째 좌안 안저는 편평하게 유지되었고 최대교정시력은 0.1로 회복되었다(Fig. 3). 


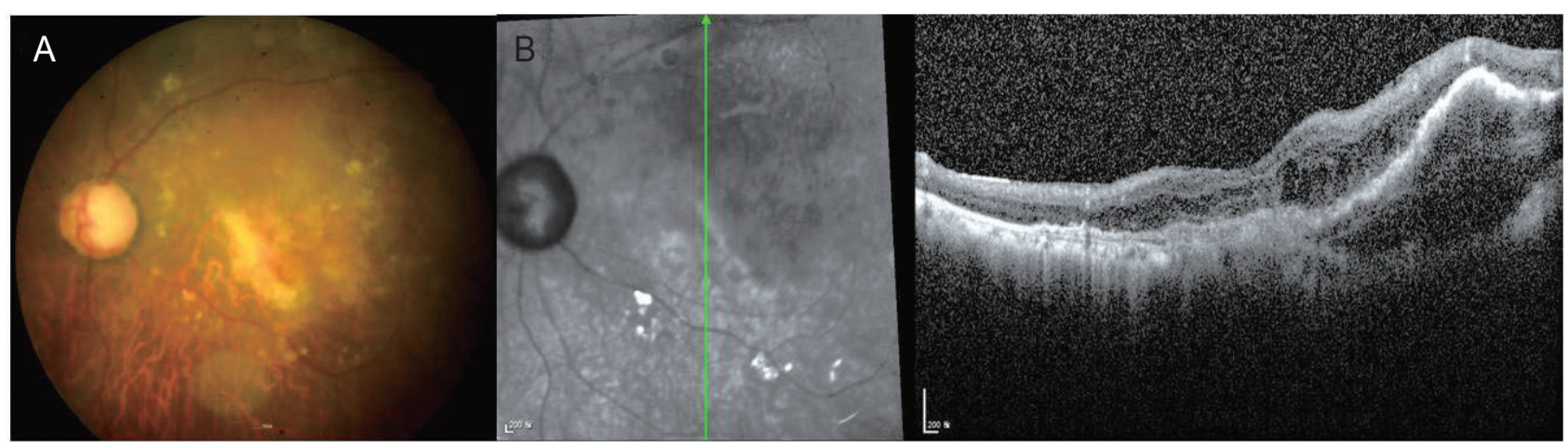

Figure 3. Fundus examination (A) and optical coherence tomography (B) 3 months after reoperation. Retina is reattached well on fundus examination and optical coherence tomography.

\section{고찰}

기존의 문헌들을 살펴보면 $\mathrm{AMD}$ 환자에서 $\mathrm{PDT}$ 를 시행한 후 초 기에 일시적인 후극부의 장액 망막박리는 드물지 않은 것으로 여겨진다. Mennel et al. [8]은 10명의 전형 맥락막신생혈관 및 잠 복 맥락막신생혈관 환자에 대하여 PDT를 시행하고 2일, 7일째 $\mathrm{OCT}$ 를 시행하였다. 그 결과 2일째 모든 환자에서 후극부의 장 액망막박리가 확인되었고 중심망막두께가 평균 $626 \pm 157 \mu \mathrm{m}$ 로서 시술 전 $217 \pm 42 \mu \mathrm{m}$ 에 비해 증가하였으나 7일째에는 망 막하액이 흡수되고 중심망막두께가 다시 $240 \pm 36 \mu \mathrm{m}$ 로 감소 하는 경향을 보였다.

$\mathrm{PCV}$ 에서도 $\mathrm{PDT}$ 후 발생한 장액성 망막박리가 발생한 증례 가 보고된 바 있다. Tobita et al. [9]은 PDT 후 7일째 광범위한 망막박리가 발견되어 테논낭하 트리암시놀론 주입술을 시행하 고 8주째 망막하액이 거의 흡수된 증례를 보고하였다. Prakash and Han [10]은 PCV에 대한 PDT 후 2일째 시력 저하 및 하부 의 광범위한 망막박리가 발생한 증례를 보고하였다. 열공망막 박리로 의심하고 공막돌륭술을 시행하였으나 수술 중 열공은 발견할 수 없었다고 하였다. 수술 3주 후 망막하액이 흡수되고 시력은 회복되었으나 4개월 후 PCV 재발로 다시 PDT를 시행 하였고 2일 후 또 망막박리가 발생하였지만 2주째 자연흡수되 었다고 보고하였다.

$\mathrm{PDT}$ 후 발생하는 장액망막박리의 기전은 완전히 밝혀지지는 않았으나 몇 가지 설명이 가능하다. PDT에 의해서 신생혈관으 로부터 누출이 일시적으로 증가하거나 망막색소상피의 손상으 로 인해 혈액망막장벽이 파괴되어 발생할 수 있다[8]. 망막색소 상피 펌프 기능 저하 및 맥락막혈관 투과성의 증가나 레이저를 조사 받은 맥락막혈관에서의 혈관내피성장인자 증가도 가능한 기전으로 설명된다[10].
본 증례에서는 기존 보고들과 비교하여 몇 가지 차이점이 있 다. 유리체절제술을 시행한 상태였고 광범위한 망막하 출혈이 동반되어 있었다. 유리체가 제거된 상태이므로 유리체의 망막 에 대한 압력이 소실되고 이미 존재하고 있던 망막하 출혈이 망 막의 유착력을 저하시켜 망막의 박리를 용이하게 한 것으로 추 정해 볼 수 있다. 따라서 본 증례에서는 환자의 유리체망막상태 로 인해 장액망막박리가 기존의 증례들에 비해 더 광범위하게 발생하고 장기적으로 유지되었다고 판단된다.

$\mathrm{PDT}$ 후 광범위한 망막박리로 인해 유리체강내로 접근하여 망 막하액 배액을 통한 망막유착술을 시행한 경우는 지금까지 보 고된 적이 없다. 이에 보고하는 바이며 PDT를 시행할 때 유리 체절제술 후 상태 혹은 광범위한 망막하 출혈이 있는 경우에는 삼출망막박리에 대한 주의를 기울일 필요가 있다고 생각한다.

\section{Conflicts of interest}

There are no conflicts of interest.

\section{References}

1. Kaiser PK; Treatment of Age-Related Macular Degeneration with Photodynamic Therapy (TAP) Study Group. Verteporfin therapy of subfoveal choroidal neovascularization in age-related macular degeneration: 5-year results of two randomized clinical trials with an open-label extension: TAP report no. 8. Graefes Arch Clin Exp Ophthalmol 2006;244:1132-42.

2. Bressler NM; Treatment of Age-Related Macular Degeneration with Photodynamic Therapy (TAP) Study Group. Photodynamic therapy of subfoveal choroidal neovascularization in age-related macular degeneration with verteporfin: two-year results 
of 2 randomized clinical trials-tap report 2. Arch Ophthalmol 2001;119:198-207.

3. Bressler NM. Verteporfin therapy of subfoveal choroidal neovascularization in age-related macular degeneration: two-year results of a randomized clinical trial including lesions with occult with no classic choroidal neovascularization-verteporfin in photodynamic therapy report 2. Am J Ophthalmol 2002;133:168-9.

4. Koh A, Lee WK, Chen LJ, et al. EVEREST study: efficacy and safety of verteporfin photodynamic therapy in combination with ranibizumab or alone versus ranibizumab monotherapy in patients with symptomatic macular polypoidal choroidal vasculopathy. Retina 2012:32:1453-64.

5. Kramer M, Miller JW, Michaud N, et al. Liposomal benzoporphyrin derivative verteporfin photodynamic therapy. Selective treatment of choroidal neovascularization in monkeys. Ophthalmology 1996;103:427-38.

6. Azab M, Benchaboune M, Blinder KJ, et al. Verteporfin therapy of subfoveal choroidal neovascularization in age-related macu- lar degeneration: meta-analysis of 2-year safety results in three randomized clinical trials: Treatment Of Age-Related Macular Degeneration With Photodynamic Therapy and Verteporfin In Photodynamic Therapy Study Report no. 4. Retina 2004;24:1-12.

7. Arnold JJ, Blinder KJ, Bressler NM, et al. Acute severe visual acuity decrease after photodynamic therapy with verteporfin: case reports from randomized clinical trials-TAP and VIP report no. 3. Am J Ophthalmol 2004;137:683-96.

8. Mennel S, Meyer CH, Eggarter F, Peter S. Transient serous retinal detachment in classic and occult choroidal neovascularization after photodynamic therapy. Am J Ophthalmol 2005;140:758-60.

9. Tobita H, Ohno-Matsui K, Ogawa M, et al. Transient serous retinal detachment after photodynamic therapy for polypoidal choroidal vasculopathy. Jpn J Ophthalmol 2008;52:518-20.

10. Prakash M, Han DP. Recurrent bullous retinal detachments from photodynamic therapy for idiopathic polypoidal choroidal vasculopathy. Am J Ophthalmol 2006;142:1079-81.

\section{국문초록}

\section{맥락막혈관병증에 대한 광역학 치료 후 발생한 광범위 장액망막박리}

목적: 결절맥락막혈관병증에 대한 광역학치료 후 광범위한 장액망막박리가 발생하여 수술로 망막을 재유착시킨 증례를 보고하고자 한다. 증례요약: 72세 남자가 좌안의 유리체 출혈로 유리체절제술을 시행 받았고 수술 중 후극부의 위축성 반흔 및 하부에 광범위한 망막하 출혈이 확인되었다. 시력은 수술 전 안전수지 $30 \mathrm{~cm}$ 에서 0.075 로 호전되었다. 3 주 후 빛간섭단층촬영에서 황반부 상측의 큰 망막색소 상피박리와 망막의 낭포성병변이 관찰되고 인도시아닌그린혈관조영에서 선형혈관 및 결절이 확인되어 결절맥락막혈관병증으로 판단하 고 광역학치료를 시행하였다. 2주 후 상부 시야결손 및 시력저하를 호소하였고 안저검사에서 황반 하부까지 이르는 광범위한 망막박리 가 발견되었으나 망막열공은 보이지 않았다. 이에 장액망막박리로 판단하고 항혈관내피성장인자를 주사하면서 관찰하였다. 하지만 망 막박리가 점차 황반부로 진행하여 5 개월째 망막절개 및 망막하액배액, 가스주입을 포함한 수술적 치료를 시행하였다. 이후 망막은 유 착되었으며 교정시력은 0.1 로 회복되었다.

결론: 결절맥락막혈관병증에서 광역학치료 후 일시적인 장액망막박리는 종종 발생하지만 광범위한 장액망막박리는 드물며 이 경우 수 술적 치료가 도움이 될 수 있다. 